\title{
1819-1836: la expansión norteamericana
}

Carlos Bosch Garcia

IIH-UNAM

\begin{abstract}
Análisis global de las relaciones entre la Nueva España, y después México, con Estados Unidos durante el periodo comprendido entre la firma del Tratado Adams-Onís y el conflicto de Texas.
\end{abstract}

\section{T} a aparición en América de países independientes de sello liberal, tuvo grandes consecuencias. Reforzó a los europeos partidarios de esa ideología y limitó el poder de la metrópoli española, que ya perdía su imperio. Además, estos países abrieron sus puertas al comercio europeo, sobre todo al de Inglaterra y Francia, que regularizaron las relaciones sostenidas ilegítimamente desde el siglo XVII.

La diferente naturaleza y la evolución histórica de Estados Unidos y de México explican los problemas que tuvieron durante el siglo XIX. Las diferentes filosofias de vida y su manejo, pragmático el del primero y legalista el del segundo, determinan la política agresiva de un lado y defensiva del otro.
La independencia mexicana dio paso a dos problemas, la necesidad de su reconocimiento legal por parte de la comunidad de naciones y la de establecer los limites territoriales indispensables; 1819 ofreció el último quehacer de la metrópoli en la cuestión de la frontera con Estados Unidos con la discusión entre Onís y Adams, quienes sólo dieron una solución temporal al problema.

Aunque el resultado no fue del agrado de Iturbide, México tuvo que enfrentar los problemas internacionales provocados por las ideologías que dividían al mundo, la conservadora y la liberal, la defensora del viejo régimen y la renovadora, propuesta por las revoluciones norteamericana y francesa.

$\mathrm{Al}$ no tener problema con los ideales 
europeos de legitimidad, Estados Unidos estuvo más cercano de las naciones recién nacidas pero, con el tema fronterizo, se complicó su decisión de reconocer la independencia y la discusión por la frontera se prolongó por casi medio siglo.

Estados Unidos chocó con la competencia de Inglaterra y con las pretensiones de Francia, además de con los esfuerzos españoles por recuperar el imperio al necesitar del mercado iberoamericano. Se hizo necesario cerrar el camino a las naciones europeas en sus pretensiones americanas y solucionar teóricamente el problema con la Doctrina Monroe.

En Inglaterra en cambio, se observa una evolución política y económica en la misma época porque se desarrollaba la revolución industrial y se abrían los mercados, en competencia con las dos industrias nacientes que fueron la francesa y la norteamericana. Durante la época de Castlereagh y de Wellington, admiradores de Metternich, resultó imposible encontrar una apertura, como se lograrịa en 1820 con Canning, a la muerte de Castlereagh. Canning, Peel y Huskinson fueron los responsables del retiro inglés de la Santa Alianza y del Congreso de Viena. Su política pacifista e internacionalista respetó el derecho a gobernarse y, apoyada en ese principio, Inglaterra reconoció las libertades de América.

En el caso de España hubo resentimiento metropolitano al perder las colonias y porque regía un gobierno absolutista que reclamaba derechos y se apoyaba en los principios legitimistas de la Santa Alianza. Se consentiría en ceder ante América aceptando su libertad, sólo por la imposición de las ideas liberales de María Cristina y por la precaria situación española.

En las dos ocasiones en que se rompió la estructura conservadora de España, en 1820 y en 1833 , se observa la búsqueda de contactos con las Américas, hasta llegar al reconocimiento en 1833. Ello fue obra de los liberales en los que Cristina tuvo que apoyarse para defenderse de los carlistas.

Los franceses también sufrieron la escisión entre liberales y ultrarrealistas. En 1815 gobernaron los realistas moderados, pero en 1820 , después de varios actos revolucionarios, subieron al poder los ultrarrealistas que condicionaron la actuación de Carlos X. En cuanto al reconocimiento de los países latinoamericanos, además de estas incidencias, había que contar con el parentesco de los reyes francés y español.

Carlos X llegó a obtener un simple convenio provisional con México. No fue ratificado y, cuando Luis Felipe ocupó el trono, con su gobierno impulsor del laissez-faire económico, concedió el reconocimiento. Ese rey, con su nueva industria, necesitó de mercados y de tratados de comercio, a la par que se enfrentaba a los problemas sociales del país. Cuando los franceses otorgaron el reconocimiento, se presentaron dificultades por las pérdidas en vidas y bienes de sus compatriotas residentes en México. Las reclamaciones se convirtieron en argumento que podía provocar una buena entrada de dinero. Así se desplomó la buena voluntad inicial, junto con los esfuerzos consumados para fomentarla, y se terminó en la guerra.

En las relaciones de la época, están las iniciadas por Estados Unidos que buscaba su hegemonía en el continente iberoamericano. Esa hegemonía estaba disputada por los países que, como Inglaterra, habían pasado por la revolución industrial y buscaban un mercado de consumo y de extracción de materias primas. Las naciones de Europa entraron en América 

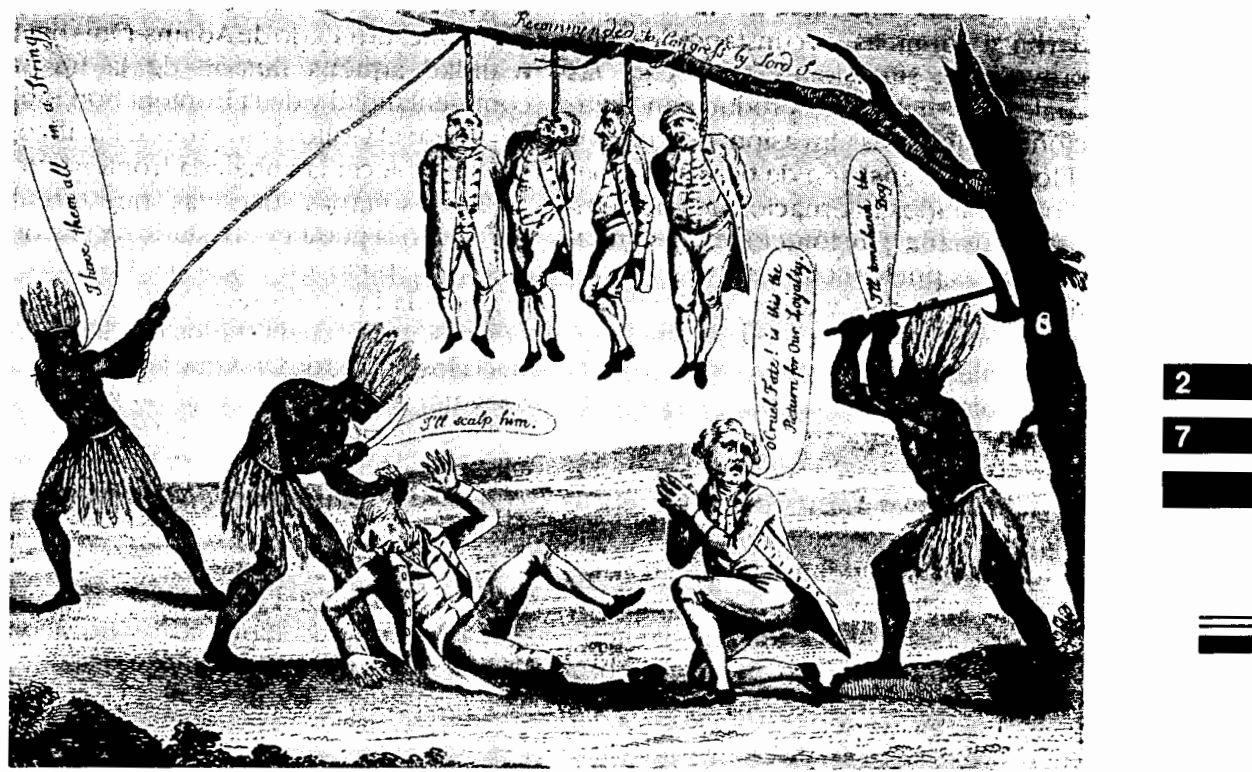

poco a poco y lograron establecer relaciones legales para firmar tratados de reconocimiento, comercio y navegación. Ese principio de la relación legal llevó a fricciones con Estados Unidos, porque chocaba con la esperanza de hegemonía, y hería los principios de suficiencia económica y de competencia, característicos de la herencia puritana religiosa norteamericana.

Con esas bases, en poco tiempo se había logrado la expansión desde el Atlántico hasta el Pacífico, ocupando los territorios a lo largo de la frontera oriental primero, saltando la cordillera hacia la cuenca del Mississippi, comprando la Luisiana, adquiriendo las Floridas, cruzando las llanuras de Utah, chocando con los linderos de Nuevo México y Alta California, para lograr, finalmente, poblarlo todo.

Esta ambiciosa política expansiva, en realidad se desarrolló paralelamente a la historia interna de Estados Unidos. Asentados en el principio de expansión interna, que convirtieron en "política externa", los norteamericanos cumplieron su tarea de imponerla durante el siglo xIX y también en el xx.

Desde un principio, en 1819 se buscó una primera línea divisoria con México -en realidad con el mundo latino- que aseguraba un mínimo de tranquilidad, aunque fuera establecida por delegados no mexicanos, Onís y Adams. Desde entonces quedó planteada la transcontinentalidad como finalidad necesaria de Estados Unidos y se constituyó la gran demarcación cultural del continente americano al separar un mundo de otro.

Con la sed de tierras y con la creencia religiosa y política en el destino manifiesto, los estadunidenses buscaron evitar la presencia de potencias europeas en 
el norte del continente. Por ello se amoldaron a formulas circunstanciales que provocaron situaciones de hecho, las cuales, al discutirse, producirían soluciones diferentes: invasión de colonos (Florida); adquisición de tierras por medio de tratados internacionales de compra (Luisiana); resoluciones de independencia por los colonos inyectados en tierras extranjeras y anexión (Texas), y expansión por medio de tratados internacionales de paz (Nuevo México, Alta California y después las Filipinas y Puerto Rico).

Después de su independencia, los nortamericanos mostraron gran preocupación por la posesión de la tierra, que consideraban la riqueza nacional necesaria para adquirir imperium. Además, al tratarse de gente trasterrada, la necesidad de seguridad se convirtió en obsesiva, porque detrás de las colonias se extendía el resto del continente hacia occidente. El tratado de Adams-Onís hizo realidad aquella ilusión de la transcontinentalidad y de la frontera horizontal, desde el Golfo de México al Pacífico, para establecer la anhelada frontera sur.

En tres etapas sucesivas, que terminaron con la guerra y el tratado de paz de 1848 , se puso en vigor la transcontinentalidad y confirmó el destino manifiesto, según el cual Estados Unidos obedecía los deseos de Dios que leencargaba asegurar la felicidad de la humanidad. Así mezclaron razones de estrategia, comunicación, comercio y política, junto con ese bienestar que dependería de la proyección de instituciones norteamericanas tales como la democracia, la forma de justicia, la moral y el temor a Dios.

Las decisiones sobre la frontera con México fueron una necesidad de ese procedimiento, que recayó con todo el peso

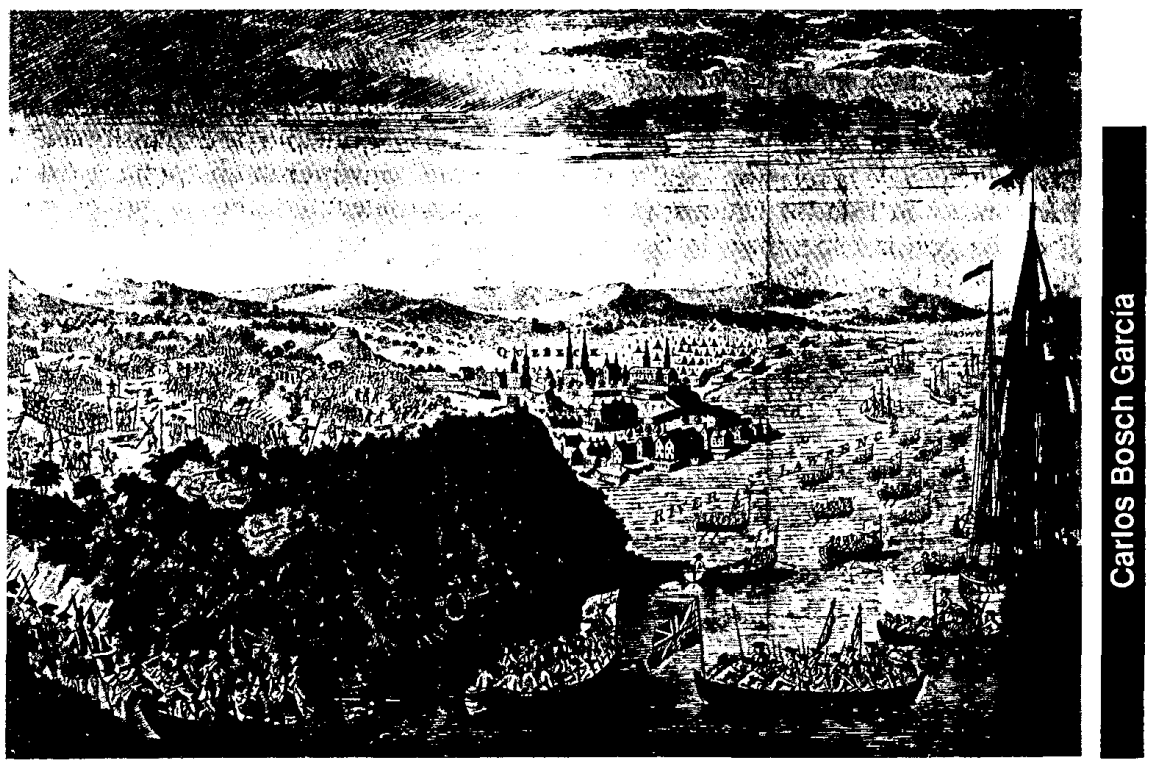


del destino sobre nuestro país. Sin embargo, la expansión no era una necesidad vital en esa época, si se consideran las dificultades que hubieron para poblar las tierras adquiridas. La necesidad real era la de especular con las finanzas y las tierras. La población agrícola, por ejemplo, tenía que caminar mucho para establecerse en tierras texanas.

Lo iniciado en 1820 entró en discusión durante los diez años siguientes cuando el planteamiento se hizo en función de las necesidades políticas de la nación estadunidense.

La base de la política externa norteamericana se formó como la proyección de problemas internos nacionales no relacionados con los internacionales al principio de la tercera década del siglo $X I X$. Era aparente la falta de fuerza nacional y de hinterland desde la época colonial, porque la tierra era la garantía de la riqueza. Desde que los colonos abandonaron Inglaterra buscaban la seguridad ante el exterior pues, con su extensión, se eliminaba o limitaba la intervención de las potencias extranjeras en el continente norteamericano.

En 1820 las naciones extranjeras contaban con la gran finanza pero Estados Unidos actuaba con los elementos tradicionales de la nación agraria, aplicados para aislar al continente de ese influjo externo. De esa manera se entiende por qué preferían una Cuba en poder de España, en vez de una nación libre y débil susceptible de caer en manos de otra potencia de Europa. Asi se dijo en las primeras instrucciones dadas al ministro Poinsett en 1824 cuando salió hacia México.

Sin duda Estados Unidos tenía un sentimiento de impotencia ante Europa, que se ve en la Doctrina Monroe enunciada en diciembre de 1823. Detrás de ella, se encuentra el fracaso diplomático de no lograr que Francia e Inglaterra se comprometieran a no agredir al continente americano. También pesó sobre Estados Unidos el temor a la presencia de Rusia en la costa noroeste continental. Por ello, la exposición de principios de Monroe anunciaba que el continente no sería objeto de futura colonización por ninguna potencia europea. ${ }^{1}$ A pesar de todo, la Doctrina Monroe tendría proyección política para más de un siglo, aunque fuera un instrumento anticuado, modificado por sus corolarios, mientras la economía financiera se mostraba como el instrumento penetrante que resultó de la revolución industrial. Así, mientras Estados Unidos hizo esfuerzos para asegurar "nuestra paz y nuestra seguridad", ${ }^{2}$ la seguridad primero nacional y luego continental se convirtió en la razón de ser, incluso de la intervención. La respuesta de Europa fue la firma de tratados de comercio, navegación y reconocimiento con las naciones americanas. Sobre todo por parte de Inglaterra que así legalizó sus relaciones con el continente.

Al iniciarse las relaciones oficiales directas de Estados Unidos con México en 1824 surgieron los problemas heredados, los endémicos de la vecindad y los procedentes de la política norteamericana en su rivalidad con esas naciones europeas. La misión de Poinsett muestra el afán de unificar el continente imponiendo el modelo norteamericano republicano, liberal, federal, masón y aún puritano. Ello significaría, a la vez, la imposibilidad de mantener los compromisos entre los latinoamericanos y europeos, sobre todo, mientras Estados Unidos se mostraba incapaz de detener las

\footnotetext{
${ }^{1}$ Samuel Flagg Bemis, La diplomacia de EstadosUnidosen la América Latina, FCE, México, 1944, p. 73 .

${ }^{2}$ Ibid., p. 74.
}

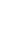

$=$ 
presiones monárquicas de los europeos ejercidas para influir en Latinoamérica. Explicamos así la intervención de los representantes norteamericanos en México y en la política de las nuevas naciones, con resultados fatales en su relación con ellas.

Por otro lado, el nuevo comercio y las finanzas británicas fueron bien recibidas en Iberoamérica porque se adaptaban a necesidades que llenaban el hueco dejado en América por España.

El mecanismo financiero inglés como producto de la revolución industrial no pudo ser contrarrestado por los gobernantes norteamericanos, desde 1812 en adelante, cuando Inglaterra perdió el interés por la posesión de la tierra en las naciones americanas. Su modernidad consistió en la práctica del comercio a gran escala y en el impulso del intercambio por la diplomacia, el capital y la marina. El todo favorecía además a la productividad de las Islas Británicas.

El choque de Estados Unidos con México, excepto en el tema de la expansión terrestre, surgió por esa lucha desigual contra Inglaterra.y su influencia en México. El intento de enfrentarse en este país a los ingleses fracasó porque éstos se adelantaron, "el presidente y los secretarios... están de su parte...", ${ }^{3}$ decía Poinsett con amargura. La única salida fue la intervención en política mediante la organización de instrumentos manipulables como las logias yorkinas, la promoción del partido liberal, la discusión, la división del Congreso y la federación. No había otra forma de hacerlo dacla la distancia a que se encontraban sus con-

${ }^{3}$ Poinsett a Clay, México, 4 de junio de 1825 , México,J. R. Poinsett, Department of State, vol. I, doc. 3, NAW.

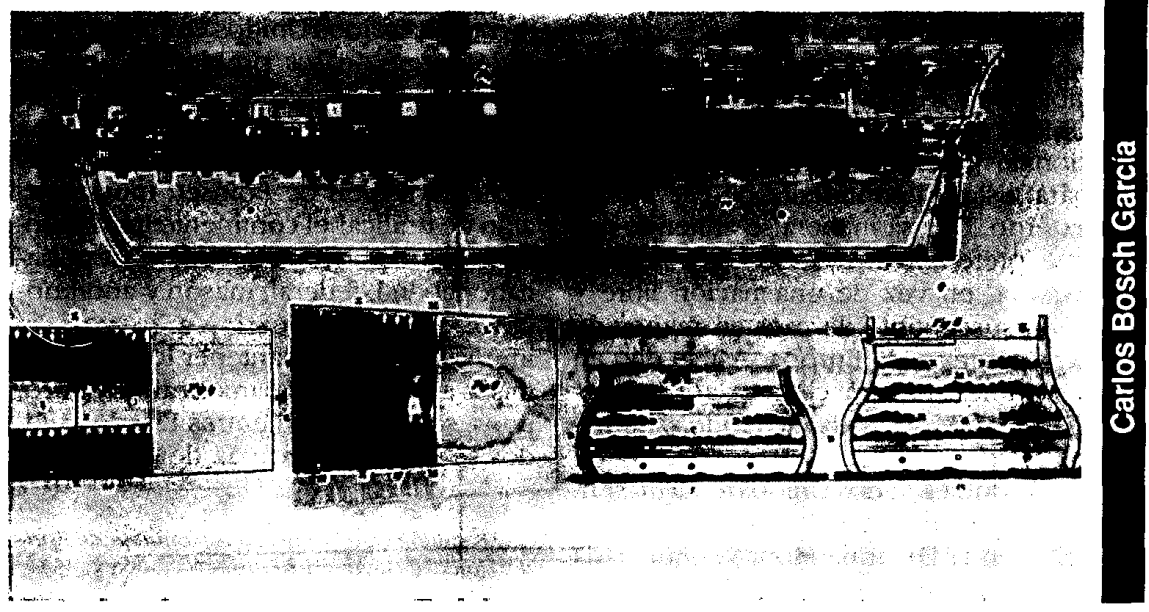


trincantes con los nuevos recursos financieros y diplomáticos. La víctima fue México porque, en relativamente poco tiempo, Poinsett logró el apoyo de un grupo respetable en ambas cámaras y consideraba que una "vasta mayoría del pueblo está en favor de la mas estricta unión con Estados Unidos". ${ }^{4}$ Ahí está explícito uno de los graves errores de la diplomacia norteamericana que, por lo general, proyecta sus valores al exterior, en este caso Poinsett no entendió el verdadero significado de "pueblo" que, en la política mexicana de la época, correspondía a los niveles sociales superiores. Por ello se hundieron los esfuerzos de Poinsett hasta el punto de que lo retiraron-después de intervenir enla llegada de Guerrero a la presidencia- por haber

\footnotetext{
${ }^{4}$ Poinsett a Clay, México, 12 de octubre de 1825 , México, J. R. Poinsett, vol. I, doc. 24, NAw.
}

provocado la protesta de Veracruz y más tarde de Montaño, opuestos a la masonería y a su política.

Si ése fue el resultado de su intervención en la política mexicana, la otra faceta de su diplomacia fue ir en busca de la expansión terrestre. El tema era típico de la historia de su país, y constituía la única respuesta para contrarrestar el retraso que tenían ante Inglaterra por no haber alcanzado la revolución industrial. El tema de la expansión fue el núcleo de la verdadera actuación diplomática, que significó hablar de tratados, fronteras y construcción de vías de comunicación entre los dos países.

De ahí surgió la política imperialista terrestre de Estados Unidos, que caracterizaría la primera mitad del siglo XIX, mientras la posesión de la tierra siguió como símbolo de riqueza para los norteamericanos, hasta cambiarse a media-

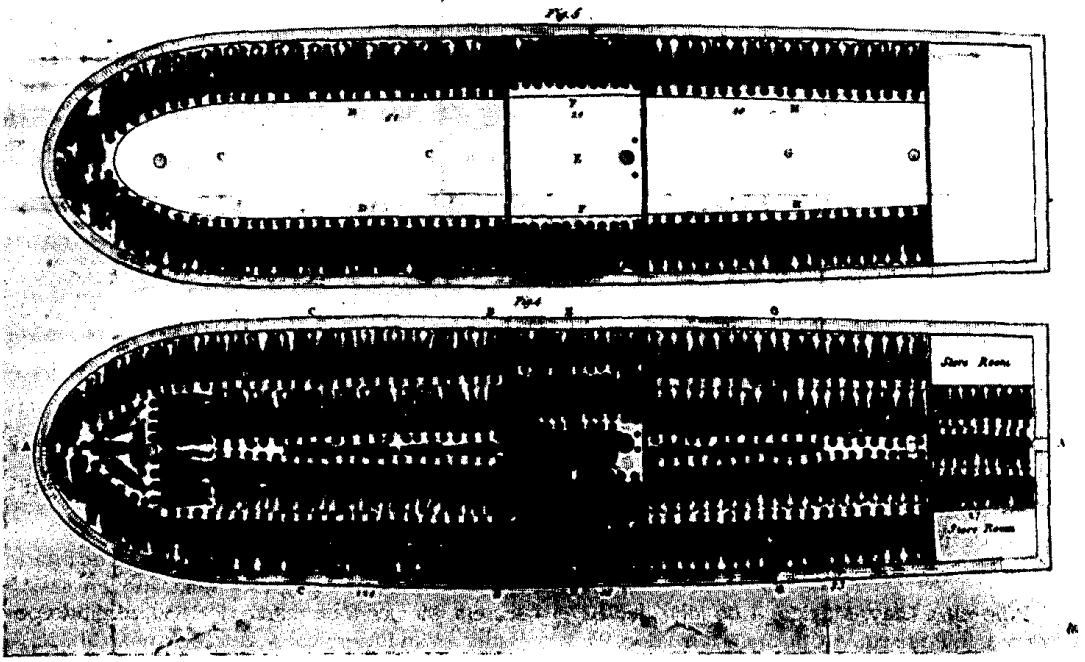


dos de siglo por la riqueza de la economía. Poinsett, Butler, Ellis, Thompson, hasta llegar a Trist, no siguieron otro camino y no tuvieron otro significado que el de desarrollar el imperio terrestre. Elúniconuevo elemento no previsto que introdujeron fue el de las reclamaciones que, a partir de Butler, se convirtieron en un instrumento de apoyo y de coerción para defender las líneas descritas.

El manejo de la política que Poinsett inició, fue el instrumento diplomático destinado a resolver los problemas de comercio y territorio usando las logias de York que formó y enfrentó con las escocesas, favorecedoras del centralismo y opuestas a los republicanos federales amigos de Estados Unidos. ${ }^{5}$

La oposición causada por estos métodos hizo fracasar las propuestas de Poinsett para el cambio de la línea fronteriza. La resistencia que le opuso México fue pasiva y burocrática, pues a toda costa retrasó los acontecimientos y el ministro se vio obligado a firmar los tratados tal como se hicieron en 1819, sin lograr la ratificación del de límites a pesar de ser el primero del México independiente, y tampoco del de comercio.

Los propios grupos liberales impulsados por Poinsett provocaron un sentimiento nacional que reforzó la resistencia contra el extranjero, contra su política y contra quien lo había impulsado. En ese sentido, Poinsett fue un impulsor del nacionalismo incipiente, que se volvió en su contra a pesar del liberalismo. Su retiro llegó a ser de interés público para Estados Unidos.

Las relaciones con México volvieron al cauce determinado por las características de la economía agraria, al tema de

S Poinsett a Clay, México, 4 de julio de 1827 , México, J. R. Poinsett, vol. III, anexo $\mathrm{B}$ al doc. 94, y 8 de julio de 1827, ibid., doc. 107, NAw. la tierra que fue, junto con las reclamaciones, la peculiaridad de la misión de Anthony Butler.

Los ministros sucesores de Poinsett siguieron los derroteros trazados por él y se amoldaron a las circunstancias que se producían. Así por ejemplo, Butler, relacionado con el grupo terrateniente de Texas, atacó a su antecesor por inepto y emprendió una violenta campaña para lograr el cambio de la frontera que auspiciaba el desarrollo del imperio, típico de la economía agraria. ${ }^{6}$

Aunque la política mexicana dio un vuelco y cambiaron los funcionarios, la violencia en las discusiones por la frontera fue constante. A pesar de ello Butler continuó impávido con su objetivo por haber llegado a México con el encargo de conseguir la región de Texas para su país, y en ello perseveró hasta el final de su misión.

Pretendió atenuar las dificultades con 5000000 de dólares y propuso líneas alternativas a la divisoria. Ahí empezó la lucha de México contra la expansión norteamericana en la frontera de su territorio, que también lo era de Iberoamérica, sin mayor recurso que abogar por el respeto a los tratados, que daba lugar a la defensa de la soberanía nacional.

Los métodos usados por Butler carecieron de todo escrúpulo y fueron variando de forma: desde las conferencias violentas hasta el maquiavelismo de la confusión y la mentira, ${ }^{7}$ enfrentándose con la postura firme y de respeto a los tratados establecidos, de la que los me-

${ }^{6} \mathrm{El}$ Sol, periódico oficial de México, 9 de enero de 1830 .

${ }^{7}$ Informe presentado por el secretario de Estado Lucas Alamán al Congreso mexicano en sesión secreta, México 8 de marzo de 1830 , remitido por Butler a Van Buren, vol. v, doc. 2 y anexo al doc. 3 , NAW. 


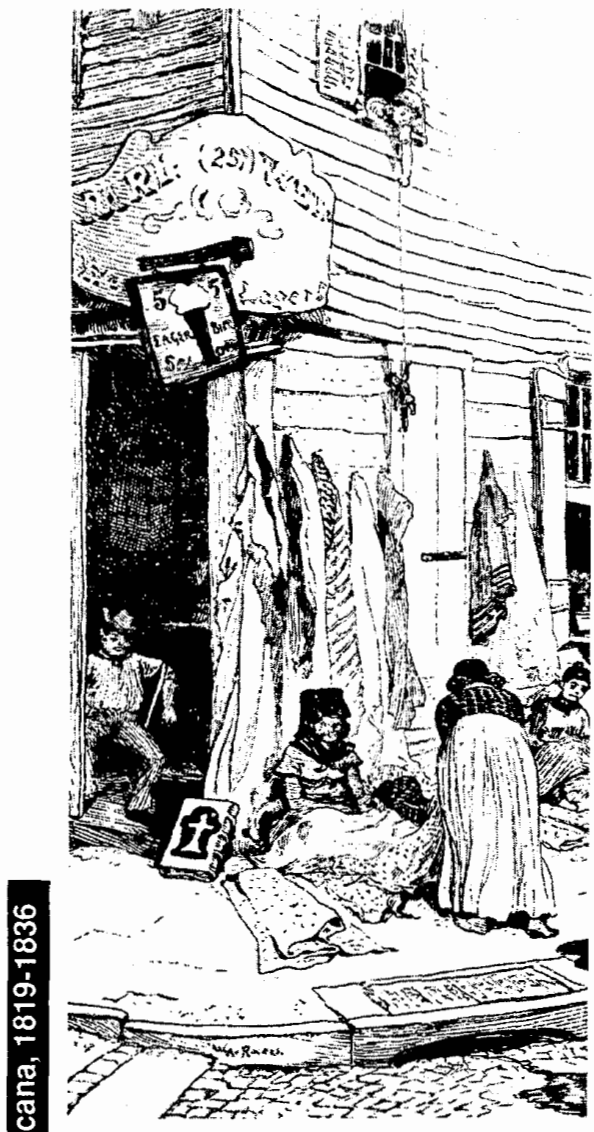

xicanos no podían salir. La intención del ministro era mover la frontera hacia el oeste y absorber los intereses norteamericanos allí establecidos. Así se procedió en 1832, hasta que el gobierno mexicano se negó a conferenciar sobre ese asunto con Butler, ${ }^{8}$ quien llegó a perder el

${ }^{8}$ Segunda conferencia entre Butler y Alamán, México, 10 de julio de 1832, México, A. Butler, vol. v, s.n., NAW. equilibrio de la realidad en marzo de 1835, al lanzar su fantasía y pensar que todo se resolvería con un soborno de 500000 dólares, invertidos a través de Ignacio Hernández, supuesto confesor de la hermana de Santa Anna. Mientras, México siguió pidiendo el respeto a los tratados. ${ }^{9}$

Así -siendo responsables esos dos primeros ministros, representantes de Estados Unidos en México- se forjó la política a seguir, resultando de las necesidades planteadas a principios del siglo, primero por la defensa de los propios Estados Unidos, que durante el siglo se ampliaria hasta convertirla en la defensa continental; después por la proyección de la economía agraria expansiva acompañada de razones económicas como la especulación de las tierras; más tarde por la estrategia que planteó desde el principio la transcontinentalidad al vislumbrar la posible extensión de océano a océano; finalmente, por el temor a la participación de las grandes potencias europeas en los asuntos americanos.

Temores y rivalidades que se fueron expresando y que recayeron en México de manera despiadada.

Observamos que todo esto sucedió durante la estancia de Poinsett y de Butler en sus respectivas misiones en México y que el resto del siglo XIX no fue otra cosa que la aplicación de la política así formada, acompañada del reflejo de los cambios que se produjeron en la política interna de Estados Unidos.

México, en cambio, tuvo que actuar frente a esa avalancha con los únicos instrumentos que pudo utilizar, las razones legales que constituyen la defensa típica del país débil.

\footnotetext{
${ }^{9}$ Butler a I. Hernández, México, 17 de marzo de 1835 y viceversa 21 de marzo, México A. Butler, vol. vi, s.n., NAw.
} 


\section{SECUENCIA}

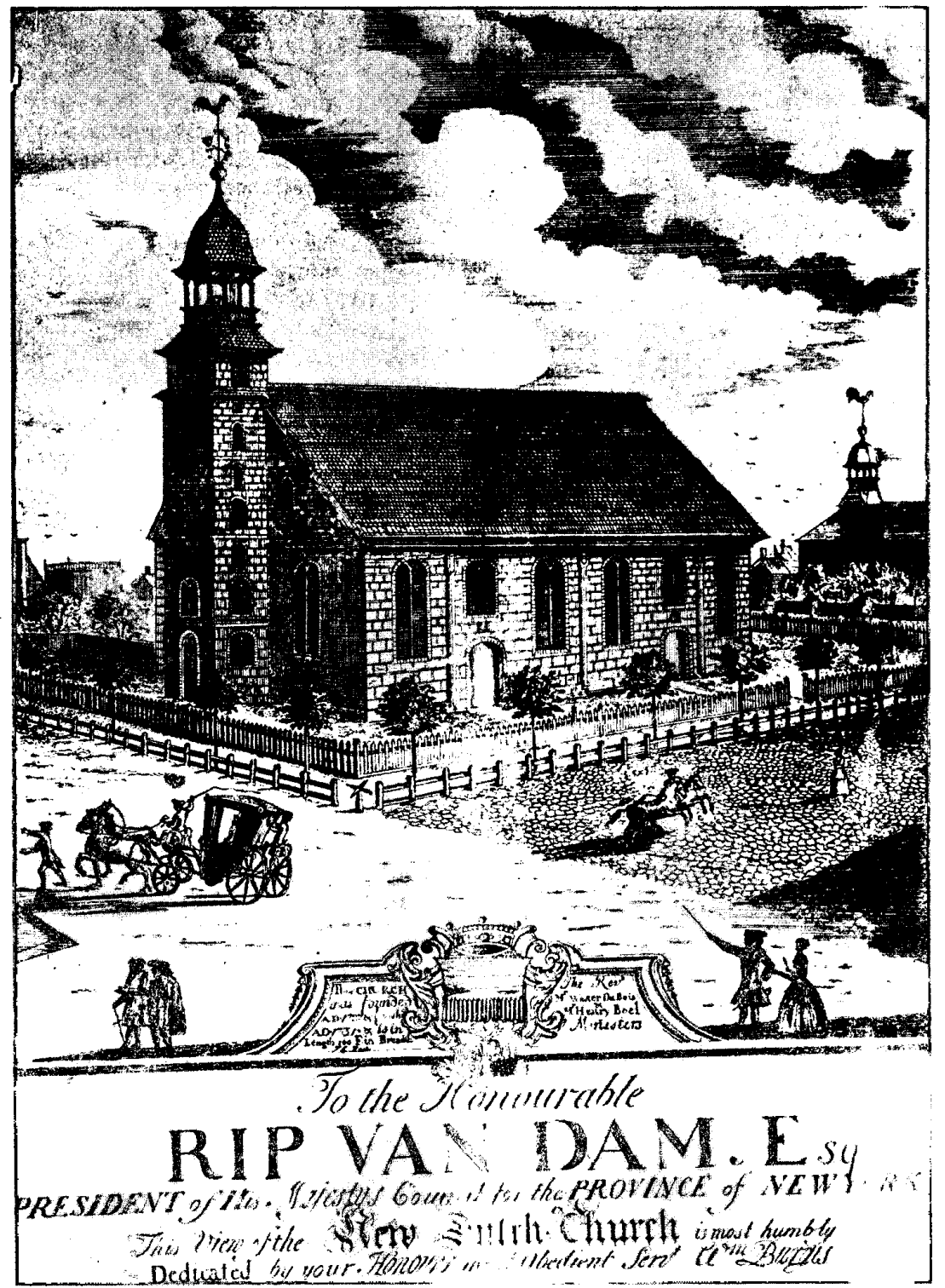

